DOI: $10.4274 /$ tod. 46220

\title{
HIV ve Osteoporoz: 3 Olgu ve Kısa Bir Derleme
}

\author{
HIV and Osteoporosis: Three Case Reports and Review of the Literature
}

Kerem Gün, Birgül Mete*, Hamza Sucuoğlu, Murat Uludağ, Mücahit Yemişen*, Ülkü Akarırmak

İstanbul Üniversitesi Cerrahpaşa Tıp Fakültesi, Fiziksel Tıp ve Rehabilitasyon Anabilim Dalı, İstanbul, Türkiye

*istanbul Üniversitesi Cerrahpaşa Tıp Fakültesi, Klinik Bakteriyoloji ve Enfeksiyon Hastalıkları Anabilim Dalı, Istanbul, Türkiye

\section{Özet}

HIV enfeksiyonu olan kişilerde beklenen yaşam süreleri antiretroviral tedavilerin kullanıma girmesi ile anlamlı düzeyde uzamıştır ve bu durum yeni sağlık sorunlarını da beraberinde getirmiştir. Bu sorunlardan biri de kemik mineral yoğunluğunda gelişebilecek kayıplardır. Yapılan çalışmalarda HIV pozitif hastalarda osteoporoz \%26 ve osteopeni \%67 oranında bildirilmiştir. Bu hastalarda ek risk faktörleri fiziksel hareketsizlik, yetersiz beslenme, D vitamini eksikliği, düşük VKi'dir. Bu nedenle klinisyenin HIV pozitif hasta takibinde osteoporoz ve ölümle dahi sonuçlanabilecek osteoporotik kırık riskini de göz önünde bulundurması önem arz etmektedir. Bu yazımızda HIV enfeksiyonu ve osteoporoz ilişkisi literatür eşliğinde tartışılarak üç olgu örneği verilmiştir. (Türk Osteoporoz Dergisi 2012;18:27-30)

Anahtar kelimeler: HIV, osteoporoz, antiretroviral tedaviler

\section{Summary}

Life expectancy in Human Immunodeficieny Virus (HIV) infection patients has increased as a result of highly active antiretroviral treatment, causing a chronic disease process. Treatment agents as well as the longer lasting disease itself seem to bring about new problems. One of these problems is bone loss which was reported to occur frequently in various studies; osteoporosis in $26 \%$ and osteopenia in $67 \%$ in HIV positive patients. Additional risk factors in these patients were physical inactivity, inadequate nutrition, vitamin D deficiency, low BMI etc. The aim of this case report was to describe clinical findings in three patients we have followed, one with compression fracture and to discuss treatment. (Turkish Journal of Osteoporosis 2012;18:27-30)

Key words: HIV, osteoporosis, antiretroviral therapies

\section{Giriş}

Insan Bağışıklık Yetmezlik Virüsü (Human Immunodeficieny Virus) (HIV) enfeksiyonu olan kişilerde beklenen yaşam süreleri, Yüksek Düzeyde Aktif Antiretroviral Tedavilerin (YDAAT) kullanıma girmesi ile anlamlı düzeyde uzamıştır ve artık bu virüsün "ölümcül" bir hastalıktan çok "kronik" bir hastalığa yol açtığı kabul edilmektedir $(1,2)$. Ancak uzayan yaşam süreleri, hastalığın kendisinin veya tedavisinde kullanılan ajanların neden olduğu, yeni sağılk sorunlarını da beraberinde getirmiştir. Bu sorunlardan biri de kemik yoğunluğunda ortaya çıkan kayıplardır. Nitekim yapılmış araştırmalarda HIV pozitif olgularda osteoporoz sıklığı \%26 (3), osteopeni sıklığı ise \%67'lere (4) varan oranlarda bildirilmiştir.

\section{Etyopatogenez}

Kemik mineral yoğunluğunda azalma, HIV pozitif olguların kronik döneminde ortaya çıkan diğer birçok sağlık sorunu gibi, hastalığın bizzat kendisi ile ilişkili olabileceği gibi, tedavide kullanılan proteaz inhibitörleri (Pi), nukleozid revers transkriptaz inhibitörleri (NRTi), nükleozid olmayan revers transkriptaz inhibitörleri (NORTi) gibi antiretroviral tedavilerden de kaynaklanabilmektedir (5). Ayrıca HIV pozitif olgularda daha sık rastlanan fiziksel inaktivite, immobilite, düşük vücut kitle indeksi, yetersiz beslenme, lipoatrofi, yetersiz kalsiyum ve D vitamin alımı, sigara, alkol veya opioid kullanımı, düşük testosteron seviyeleri gibi konağa ait diğer bazı etkenler de risk faktörleri arasında sayılabilir (Tablo 1) $(5,6)$.

Yazışma Adresi/Address for Correspondence: Dr. Hamza Sucuoğlu, İstanbul Üniversitesi Cerrahpașa Tıp Fakültesi, Fiziksel Tıp ve Rehabilitasyon Anabilim Dalı, İstanbul, Türkiye Gsm: +90 5056297688 E-posta: hamzasucuoglu@mynet.com.tr Geliș Tarihi/Received: 10.05.2012 Kabul Tarihi/Accepted: 07.06.2012

Türk Osteoporoz Dergisi, Galenos Yayınevi tarafından basılmıştır. / Turkish Journal of Osteoporosis, published by Galenos Publishing. 


\section{a- HIV ve Kemik Demineralizasyonu}

Antiretroviral tedavi almayan HIV pozitif olgularda da yüksek osteopeni/osteoporoz sıklığının gözlenmesi $(7,8)$ ve hastalık süresi ile kemik demineralizasyonu arasındaki ortaya konan korelasyon (8) HIV enfeksiyonunun bizzat kendisinin kemik demineralizasyonuna neden olabileceğinin bir göstergesidir. HIV ile ilişkili kemik kaybı çok sebeplidir ve karmaşık bir temele dayanır. HIV viral proteinlerinin osteoblast fonksiyonu üzerinde baskılayı ı etkisinin yanında $(9,10)$ osteoklastik aktiviteyi arttırıc özelliklerinden de bahsedilebilir (11). Bunun dışında HIV enfeksiyonunun neden olduğu sistemik inflamasyon da kemik yapım ve yıkımında etkili olmaktadır (12). Özellikle Reseptör Aktivatör Nükleer Faktör Kappa (RANK), Makrofaj Koloni Stimule Edici Faktör (M-CSF) ve Tümör Nekroze Edici Faktör Alfa (TNF- $\alpha)^{\prime}$ nın osteoklast gelişimi ve aktivitesini artıcı etkileri HIV enfeksiyonunun sistemik etkileri ile şiddetlenebilir (5). Bu anlamda bazı araştırmalar HIV yükü ile TNF $\alpha$ konsantrasyonu arasında (13)

\section{Tablo 1. Epidemiyolojik çalıșmalarda HIV pozitif olgular için} ortaya konmuș osteopeni ve osteoporoz risk faktörleri (5)

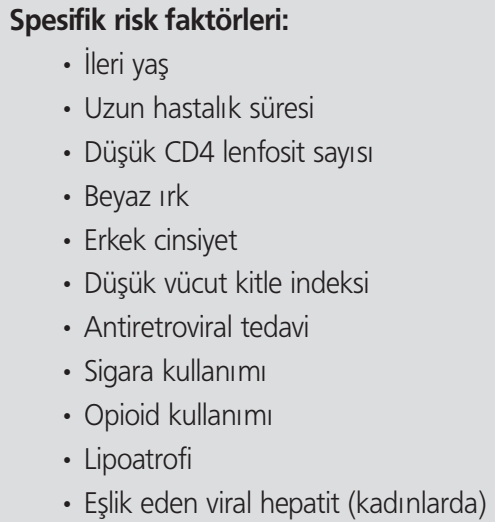

\section{Genel risk faktörleri:}

- Menopoz

- Fiziksel inaktivite

- Yoğun alkol kullanımı (>16 g/gün)

- Yetersiz beslenme

- Hipogonadizm

- Kortikosteroid kullanımı ve kemik rezorbsiyon belirteçleri ile TNF $\alpha$ aktivasyonu arasında bağıntı ortaya koymuşlardır (14). Ayrıca enfeksiyona bağlı gelişen laktik asidemi ve birlikte görülebilen fırsatçı enfeksiyonlar da osteoporoz gelişiminde etkili olan diğer faktörlerdir (15-17).

\section{b- Antiretroviral Tedaviler ve Kemik Demineralizasyonu}

YDAAT'nin HIV enfeksiyonundan bağımsız olarak kemik döngüsü üzerine etkisi çeşitli araştırmaların konusu olmuştur. Bu araştırmaları inceledikleri yakın tarihli meta-analizlerinde Brown ve Qaqish, antiretroviral tedavinin HIV pozitif olgularda osteoporoz gelişme riskini 2.4 kat arttırdığını ancak etki mekanizmalarının tam anlamı ile açıklığa kavuşmadığını belirtmişlerdir (2). Bu terapötik ajanların kullanımı ile özellikle tedavinin 48 ila 96 haftalık ilk döneminde \%6'ya ulaşabilen kemik mineral kaybı olduğu, bu dönemi plato döneminin izlediği üzerinde durulmaktadır. Ancak bu ajanların kemik metabolizması üzerine uzun dönem etkileri konusu halen açıkığa kavuşmamıştır $(5,18-20)$.

HIV pozitif olguların tedavisinde genelde 2 NRTi'ye ek olarak diğer PI veya bir NORTi kombine edilir. Daha nadir olarak ise iki Pi veya 3 NRTi birlikte kullanılır (21). Kullanılan antiretroviral ajan türü veya tedavi protokolü ile kemik mineral yoğunluğu kayıp şiddeti arasında kesin bir ilişki ortaya konamamış olsa da yapılan araştırmalarda bu ajanlardan özellikle Pi grubunun ve NRTi'lerden tenofovirin kemik metabolizmasına olumsuz etkilerinin ön plana çıktığı söylenebilir (2,

5). Antiretroviral ilaçlar kemik formasyonunu direkt olarak osteoblast veya osteoklastik aktivite üzerinden etkileyebildiği gibi vitamin $D$ /parathormon/kalsiyum/fosfat döngüsü üzerinden indirekt olarak da etki gösterebilir (Tablo 2).

\section{Tanı}

Her ne kadar daha farklı önerilerde bulunan araştırmacılar olsa da (22), mevcut enfeksiyonları ve kullandıkları ilaçların kemik mineral yoğunluğu üzerine etkileri nedeniyle tüm HIV pozitif olgular, detaylı bir osteoporoz- osteoporotik kırık risk sorgulaması ve ayrıntılı muayene sonrası DXA ölçümü için adaydır. DXA uygulaması, herhangi bir engel yoksa, standart bölgelerden yapılır ve kemik mineral yoğunluğunda $-2,5$ standart sapmanın üzerindeki kayıplar medikal tedaviyi gerektirir. Ek olarak osteopeni ve osteoporoz için sekonder nedenleri ortaya koyabilmek ve en ideal tedaviyi çizebilmek

Tablo 2. Antiretroviral ajanların kemik döngüsü üzerine olası etkileri (5)

\begin{tabular}{|c|c|c|c|}
\hline ARA & \multicolumn{2}{|c|}{ Kemik Hücresel Kompartmanı } & \multirow[t]{2}{*}{ Vit D / PTH / Fosfat dengesi } \\
\hline & Osteoblastik aktivite & Osteoklastik aktivite & \\
\hline Pi & $\begin{array}{c}\text { Azalma } \\
\text { (Indinavir,Ritonavir) }\end{array}$ & $\begin{array}{c}\text { Artış } \\
\text { (Sakinavir,Ritonavir, Nelfinavir,Indinavir) }\end{array}$ & $\begin{array}{c}25 \text { hidroksilaz ve } 1 \alpha \text { hidroksilaz inhibisyonu } \\
\text { (Ritonavir, Indinavir, Nelfinavir) }\end{array}$ \\
\hline NRTi & & $\begin{array}{c}\text { Artış } \\
\text { (Zidovudin, Didanozin, Lamivudin) }\end{array}$ & $\begin{array}{l}\text { Böbrek ve barsakta fosfat kaçağı (Tenofovir) } \\
\text { Plasma PTH seviyelerinde artış (Tenofovir) } \\
1 \alpha \text { hidroksilaz fonksiyonunda azalma (Tenofovir) }\end{array}$ \\
\hline NORTi & & & $\begin{array}{c}24 \text { hidroksilaz artışı ile } 25 \text { hidroksi vitamin } \\
\text { D metobolizma hızında artış }\end{array}$ \\
\hline
\end{tabular}


için hemogram, serum kalsiyum ve fosfor düzeyleri, renal ve hepatik fonksiyonlar, total protein düzeyleri, total kolesterol düzeyleri, alkalen fosfataz, serum vitamin D düzeyleri ve diğer ek tetkikleri istenebilir (6).

\section{Tedavi}

HIV pozitif olgularda temel osteopeni ve osteoporoz tedavi protokollerinde normal populasyona göre büyük farklılıklar bulunmamaktadır. Öncelikli hedef farmakolojik olmayan yaklaşımlar ile kemik mineral yoğunluğunun arttırılması, kemik destek dokularının kuvvetlendirilmesi, düşme riskinin azaltılması ve kişinin yaşam tarzının modifiye edilmesidir. Diyet ile kalsiyum alımının arttırıması için süt ve süt ürünlerinin alımının teşvik edilmesi ve bunun günlük 1200 mg Ca 2+ düzeyine ulaşacak şekilde kalsiyum preparatları ile takviye edilmesi önemli bir ilk basamaktır $(5,6)$. HIV pozitif olgularda \%60-75 oranında vitamin D yetersizliği bulunduğu (23-25) göz önünde alındığında kişinin günlük 800-1000 iU vitamin D alması ve güneşten yararlanmasının sağlanması da gereklidir. Bunun dışında tuz, kahve ve alkollü içeceklerin azaltılması, tütünün bırakılması, inaktiviteden uzaklaştırılıp günlük fiziksel aktivite programlarının düzenlenmesi gibi standart osteoporoz tedavi protokolleri bu hastalara da uygulanmalıdır. Ayrıca malnutrisyon, uyuşturucu kullanımı, hipogonadizm gibi HIV pozitif olgularda daha sık gözlenen durumlar akılda bulundurulmalıdır. Özellikle düşme riskinin azaltılması ve kemik dokuya destek sağlanması açısından kas kuvvetlendirme, denge - koordinasyon ve yürüme egzersizlerinin hastanın hayatına sokulması ve çevresel faktörlerin düzeltilmesi önemlidir $(21,26)$. Diğer yandan HIV enfeksiyonu ile ilişkili diğer ek hastalıkların tespit ve tedavisi üzerinde de durulmalıdır (26).

HIV pozitif olguların osteoporoz tedavisinde araştııımış farmakolojik ajan bifosfonatlardır. Alendronat ile ilgili 3 randomize çalışma (27-29) oral bifosfonatların HIV pozitif olgularda etkin ve tolere edilebilir olduğunu ortaya koymuştur. Bifosfonatların gastrointestinal yan etkileri göz önünde bulundurulduğunda zoledronik asit infüzyonunun uygun ve etkili diğer bir seçenek olduğu söylenebilir $(30,31)$.

\section{Sonuç}

HIV enfekte kişilerde uzayan yaşam süreleri ile birlikte, osteoporoz ve osteopeni ek bir sağlık sorunu haline gelmiştir. Virüse, konağa ve yapılan tedaviye bağlı karmaşık ve birbirlerini etkileyen bir dizi etyolojik faktör azalan kemik yoğunluğundan sorumlu gibi görünmektedir. Tanı ve tedavisi standart osteoporoz tanı ve tedavisinden büyük farklılık göstermese de klinisyenin HIV pozitif hastasının takip ve tedavi stratejisini belirlerken osteoporoz ve ölümle dahi sonuçlanabilecek osteoporotik kırık riskini de göz önünde bulundurması önem arz etmektedir.

\section{Olgu 1}

Altı yıl önce rinoplasti operasyonu öncesi yapılan rutin tetkikler sırasında HIV enfeksiyonu tanısı konan 66 yaşında erkek hastada homoseksüel ilişki hikâyesi mevcut. Hasta tanı konduğu dönemden itibaren enfeksiyon hastalıkları kliniğinde NORTi (efavirenz 600 mg/gün) ve NRTi (tenofonir disoproksil 245 mg/gün + emtrisitabin 200 mg/gün) kombine tedavisi altında takip edilmekte. Zaman zaman olan baş ağrısı şikayeti nedeniyle nöroloji tarafından, genel vücut kaşıntısı nedeniyle dermatoloji tarafından konsulte edilen hasta, Eylül 2011 tarihinde istenen DXA ile (T skoru, femur boyun: 2,6, L1-4: -1,8) polikliniğimize yönlendirilmiş. Kliniğimizde yapılan ek tetkiklerinde $25-\mathrm{OH}$ vit $\mathrm{D}(9,8 \mathrm{ng} / \mathrm{ml})$ düzeyi düşüklüğü dışında patolojik sonuç saptanmadı. Bir ay önceki CD4 sayısı 318/mm³ olarak bulunmuş ve viral yük saptanmamıştı. VKi normal olan hastanın muayenesinde servikal ve aksiler bölgede $1-2 \mathrm{~cm}$ büyüklüğünde LAP saptandı. Bunun dışında sistemik, lokomotor ve nörolojik sistem muayenesinde anlamlı bir patoloji saptanmadı. Alışkanlıkları sorgulandığında 40 paket/yıl sigara kullanımı, 20 yıldır haftanın her günü 5-6 şişe bira tüketimi, 10 yıl süresince 2-3 ayda bir esrar kullanımı olduğu öğrenildi.

\section{Olgu 2}

Sekiz ay önce ikinci evlilik işlemleri sırasında yapılan rutin tetkikler sırasında HIV pozitif olduğu saptanan ve heteroseksüel ilişki sonucu (birinci eşi) bulaştığı anlaşılan 31 yaşında kadın hasta. Enfeksiyon hastalıkları kliniğinde NRTi (zidovudin 150 mg/gün + lamivudin 300 mg/gün) ve Pi (lopinavir 400 mg/gün + ritonavir 100 mg/gün) tedavisi ile takip edilen hasta kemik mineral yoğunluğu değerlendirilmesi için kliniğimize yönlendirilmiş. Yakınması olmayan hastanın muayenesinde servikal bölgede birkaç adet $1-2 \mathrm{~cm}$ 'lik LAP ve $2 \mathrm{~cm}$ 'lik splenomegali dışında normal saptandı. VKi normal sınırlardaydı. Özgeçmişinde ve alışkanlıklarında özellik saptanmayan hastanın osteoporoz riski açısından yapılan tetkiklerinde, DXA normal sınırlarda (T skoru, femur boyun: -0,7, L1-4: -0,8) tespit edildi ve $25-\mathrm{OH}$ vit D düzeyi 8,3ng/ml idi. Hastanın 2 ay önce bakılan CD4 sayısı 598/mm³ olarak ölçülmüş ve viral yük saptanmamıştı.

\section{Olgu 3}

Kasım 2008 tarihinde aşırı kilo kaybı nedeniyle başvurduğu merkezde yapılan tetkikler sırasında HIV pozitif olduğu anlaşılan, 1985 - 2000 yılları arasında yurtdışı seyahatleri esnasında riskli cinsel ilişki hikayesi bulunan 52 yaşında erkek hasta. Enfeksiyon hastalıkları birimince NORTi (efavirenz $600 \mathrm{mg} / g u ̈ n$ ) ve NRTi (tenofonir disoproksil 245 mg/gün + emtrisitabin 200 mg/gün) tedavisi ile takip edilirken kemik yoğunluğunun değerlendirilmesi açısından kliniğimize yönlendirilmiş. Hastanın yapılan kontrollerinde dönem dönem halsizlik, kaşıntı, boğaz ağrısı, uykusuzluk ve gerginlik gibi çeşitli şikâyetleri oluyormuş. Özgeçmişinde 30 paket/yıl sigara ve düzenli alkol kullanımı olan ve tanı konulduktan sonra kullanmayan hastanın ayrıca düşük enerjili ön kol kırığı hikayesi olduğu öğrenildi. Düşük VKI'ne sahip olan hastanın yapılan muayenesinde dorsal kifozda artış izlendi. Sistemik muayenesinde $4 \mathrm{~cm}$ hepatomegali ve $1 \mathrm{~cm}$ boyutlarında bir kaç adet servikal LAP saptandı. Çekilen dorsal 
lateral grafisinde multipl seviyelerde yükseklik kaybı (<\%25) ve kamalaşmalar görüldü. DXA ölçümünde T skoru, femur boyun: -2,7, L1-4: $-3,8$ ve serum $25-\mathrm{OH}$ vit $\mathrm{D}$ düzeyi $13,9 \mathrm{ng} / \mathrm{ml}$ olarak tespit edildi. Illk başvuru esnasında CD4: 480/mm³ , HIV-RNA: 140000 kopya/ml, Mart 2012 tarihinde yapılan ölçümlerde ise CD4: 835/mm³ olup, HIV-RNA saptanmamıştı.

Hastaların DXA skoru, mevcut enfeksiyonu ve eşlik eden risk faktörleri göz önünde bulundurulduğunda bir ve üçüncü olgularda Alendronat sodyum 70 mg/hafta, kalsiyum 1000 mg+ 880IU vitamin D3 tedavisi başlandı. Her üç olguya da düşük $D$ vitamin seviyeleri göz önünde bulundurularak 3 hafta boyunca 300 bin IU vitamin D3/hafta replasmanı uygulandı. Yine üç olguya da standart osteoporoz egzersiz programı ve günlük yaşam aktivite düzenlemeleri yapıldı. Ayrıca üçüncü olgumuza sırt ağrısı ve kompresyon kırıkları nedeniyle ek olarak parasetamol 1500 mg/gün, konvansiyonel tarzda $20 \mathrm{dk}$ günde 2 kez TENS tedavisi uygulandı ve kısa süreli korseleme yapıldı.

\section{Kaynaklar}

1. Sutinen J, Ristola M. HIV-from a lethal disease to a chronic illness. Duodecim 2012;128:37-46.

2. Brown T, Qaqish R. Antiretroviral therapy and the prevalence of osteopenia and osteoporosis: a meta-analytic review. AIDS 2006;20:2165-74.

3. Cazanave C, Dupon M, Lavignolle-Aurillac V, Barthe N, Lawson-Ayayi S, Mehsen N, et al. Groupe d'Epidémiologie Clinique du SIDA en Aquitaine. Reduced bone mineral density in HIV-infected patients: prevalence and associated factors. AIDS 2008;22:395-402.

4. Knobel H, Guelar A, Vallecillo G, Nogués X, Díez A. Osteopenia in HIVinfected patients: is it the disease or is it the treatment? AIDS 2001:15:807-8

5. Gutierrez F, Masia M. The role of HIV and antiretroviral therapy in bone disease. AIDS Rev 2011;13:109-18.

6. Lima AL, de Oliveira PR, Plapler PG, Marcolino FM, de Souza Meirelles E, Sugawara A, et al. Osteopenia and osteoporosis in people living with HIV: multiprofessional approach. HIV AIDS (Auckl) 2011;3:117-24.

7. Knobel H, Guelar A, Vallecillo G, Nogués X, Díez A. Osteopenia in HIVinfected patients: is it the disease or is it the treatment? AIDS 2001; 15:807-8

8. Bruera D, Luna N, David DO, Bergoglio LM, Zamudio J. Decreased bone mineral density in HIV-infected patients is independent of antiretroviral therapy. AIDS. 2003;17:1917-23.

9. Gibellini D, De Crignis E, Ponti C, Cimatti L, Borderi M, Tschon M, et al. HIV-1 triggers apoptosis in primary osteoblasts and HOBIT cells through TNFalpha activation. Med Virol 2008;80:1507-14.

10. Cotter EJ, Malizia AP, Chew N, Powderly WG, Doran PP. HIV proteins regulate bone marker secretion and transcription factor activity in cultured human osteoblasts with consequent potential implications for osteoblast function and development. AIDS Res Hum Retroviruses 2007;23:1521-30.

11. Fakruddin JM, Laurence J. HIV envelope gp120-mediated regulation of osteoclastogenesis via receptor activator of nuclear factor kappa B ligand (RANKL) secretion and its modulation by certain HIV protease inhibitors through interferon-gamma/RANKL cross-talk. J Biol Chem. 2003 Nov 28;278:48251-8. Epub 2003 Sep 15.
12. Kong $Y Y$, Yoshida $H$, Sarosi I, et al. OPGL is a key regulator of osteoclastogenesis, lymphocyte development and lymph-node organogenesis. Nature 1999;397:315-23.

13. Hittinger G, Poggi C, Delbeke E, Profizi N, Lafeuillade A. Correlation between plasma levels of cytokines and HIV-1 RNA copy number in HIV-infected patients. Infection 1998;26:100-3.

14. Aukrust P, Haug CJ, Ueland T, Lien E, Müller F, Espevik T, et al. Decreased bone formative and enhanced resorptive markers in human immunodeficiency virus infection: indication of normalization of the bone-remodeling process during highly active antiretroviral therapy. J Clin Endocrinol Metab 1999;84:145-50.

15. Dolan SE, Huang JS, Killilea KM, Sullivan MP, Aliabadi N, Grinspoon S. Reduced bone density in HIV-infected women. AIDS 2004;18:475-83.

16. Jain RG, Lenhard JM. Select HIV protease inhibitors alter bone and fat metabolism ex vivo. J Biol Chem 2002:277:19247-50.

17. Mora S, Sala N, Bricalli D, Zuin G, Chiumello G, Viganò A. Bone mineral loss through increased bone turnover in HIV-infected children treated with highly active antiretroviral therapy. AIDS 2001;15:1823-9.

18. Mallon PW, Miller J, Cooper DA, Carr A. Prospective evaluation of the effects of antiretroviral therapy on body composition in HIV-1-infected men starting therapy. AIDS 2003;17:971-9.

19. Gallant JE, Staszewski S, Pozniak AL, DeJesus E, Suleiman JM, Miller $M D$, et al. Efficacy and safety of tenofovir DF vs. stavudine in combination therapy in antiretroviral-naive patients: a 3-year randomized trial. J Am Med Assoc 2004;292:191-201.

20. Yin MT, McMahon DJ, Ferris DC, Zhang CA, Shu A, Staron R, et al. Low bone mass and high bone turnover in postmenopausal human immunodeficiency virus-infected women. J Clin Endocrinol Metab 2010;95:620-9

21. Saccomanno MF, Ammassari A. Bone disease in HIV infection. Clin Cases Miner Bone Metab 2011;8:33-6.

22. McComsey GA, Tebas P, Shane E, Yin MT, Overton ET, Huang JS, et al. Bone disease in HIV infection: a practical review and recommendations for HIV care providers. Clin Infect Dis 2010;51:937-46.

23. Stephensen CB, Marquis GS, Kruzich LA, Douglas SD, Aldrovandi GM, Wilson CM. Vitamin D status in adolescents and young adults with HIV infection. Am J Clin Nutr 2006:83:1135-41.

24. Rodriguez M, Daniels B, Gunawardene S, Robbins GK. High frequency of vitamin D deficiency in ambulatory HIV-Positive patients. AIDS Res Hum Retroviruses 2009;25:9-14.

25. McComsey GA, Tebas P, Shane E, Yin MT, Overton ET, Huang JS, et al Bone disease in HIV infection: a practical review and recommendations for HIV care providers. Clin Infect Dis 2010;51:937-46.

26. Arora S, Agrawal M, Sun L, Duffoo F, Zaidi M, Iqbal J. HIV and bone loss. Curr Osteoporos Rep 2010;8:219-26.

27. Guaraldi G, Orlando G, Madeddu G, Vescini F, Ventura P, Campostrini $\mathrm{S}$, et al. Alendronate reduces bone resorption in HIV-associated osteopenia/osteoporosis. HIV Clin Trials 2004:5:269-77.

28. Mondy K, Powderly WG, Claxton SA, Yarasheski KH, Royal M, Stoneman JS, et al. Alendronate, vitamin $\mathrm{D}$, and calcium for the treatment of osteopenia/osteoporosis associated with HIV infection. J Acquir Immune Defic Syndr 2005:38:426-31.

29. Negredo E, Martinez-Lopez E, Paredes R, Rosales J, Pérez-Alvarez N, Holgado S, et al. Reversal of HIV-1 associated osteopenia with onceweekly alendronate. AIDS 2005;19:243-5.

30. Bolland MJ, Grey AB, Horne AM, Briggs SE, Thomas MG, Ellis-Pegler $\mathrm{RB}$, et al. Annual zoledronate increases bone density in highly active antiretroviral therapy-treated human immunodeficiency virus-infected men: a randomized controlled trial. J Clin Endocrinol Metab 2007;92:1283-8.

31. Huang J, Meixner L, Fernandez S, McCutchan JA. A double-blinded, randomized controlled trial of zoledronate therapy for HIV-associated osteopenia and osteoporosis. AIDS 2009:23:51-7. 